\title{
A atualidade dos acidentes de trânsito na era da velocidade: uma visão geral
}

\author{
Car accidents in the age of speed: \\ an overview
}

Letícia Marín 1

Marcos S. Queiroz 2

\footnotetext{
1 Departamento de Medicina Preventiva e Social, Faculdade de Ciências Médicas, Universidade Estadual de Campinas. Rua das Orquídeas 587 Campinas, SP 13087-370, Brasil. 2 Departamento de Psicologia Médica e Psiquiatria, Faculdade de Ciências Médicas, Centro de Memória, Universidade Estadual de Campinas. Rua das Orquídeas 587, Campinas, SP 13087-370, Brasil. msq44@uol.com.br
}

\begin{abstract}
This article focuses, in an interdisciplinary perspective, the studies about traffic accidents, in a national and international scale. It starts by analysing the great increase in production and consumption of motor vehicules worldwideand the social transformations which this fact produced. Particular attention is given to the degradation of the urban environment and the enormous social costs represented by traffic accidents. It follows with an epidemiological view on the victims of traffic accidents. The relationship between personality and traffic accidents deserved special attencion, mainly in what it relates to the consumption of alcool and other chemical drugs, and other law breaking behaviour. The article concludes by emphasi sing the need of the State to implemment specif consistent public policies, in order to control the problem. Key words Automobile Driving; Motor Vehicles; Traffic Acci dents; Epidemiology
\end{abstract}

Resumo Este artigo focaliza, numa perspectiva interdisciplinar, os estudos sobre aci dentes de trânsito em escal a nacional e internaci onal. Ele começa analisando o aumento da produção e consumo de veícul os motori zados em todo o mundo e as transformações sociais que esse fato acarretou. Atenção especial é dada à degradação do mei o ambi ente urbano e ao enorme custo social representado pelos acidentes de trânsito. Em seguida, é apresentado um panorama epidemi ológico sobre as víti mas do trânsito. A relação entre personali dade e aci dente de trânsi to mereceu atenção especial, principalmente no que se refere ao comportamento infrator e ao consumo de bebidas al coól i cas e de outras drogas. O arti go concl ui enfatizando a necessi dade de o Estado implementar políticas públicas específicas consi stentes, a fim de se poder controlar o problema.

Palavras-chave Condução deVeículo; Veículos Automotres; Aci dentes de Trânsito; Epidemiologia 
Introdução

Os estudos sobre acidentes de trânsito (AT) no Brasil são escassos, as ações de prevenção e controle estão apenas iniciando e pouco se conhece a respeito do comportamento do motorista e do pedestre, das condições de segurança das vias e veículos, da engenharia de tráfego, dos custos humanos e ambientais do uso de veículos motorizados e das conseqüências traumáticas resultantes dos AT. Este artigo pretende dimensionar os trabal hos mais rel evantes sobre esse tema, em nível nacional e internacional, visando contribuir para o desenvolvimento dessa área de estudo.

Após a Segunda Guerra Mundial, o automóvel particular converte-se em fenômeno de massa em todo o mundo. Ele torna-se artigo de consumo e símbolo de status social, impulsionado pelo forte aparato de propaganda das economias capitalistas, que destacam a mobilidade individual e a prosperidade material sem precedentes. A produção mundial anual de automóveis cresceu de 11 para 53 milhões entre 1950 e 1995 (Tapia-Granados, 1998). Entre 1970 e 1988, nos Estados Unidos da América (EUA), o volume do tráfego aumentou de 1,78 trilhões de $\mathrm{km}$ percorridos por veículos para 3,24 trilhões (Roberts, 1995). O aumento da frota de veículos tem sido mundial, mas, em geral, o sistema viário e o planejamento urbano não acompanharam este crescimento. Além da poluição sonora e atmosférica, o aumento do tempo de percurso, os engarrafamentos, são responsáveis pela crescente agressividade dos motoristas e pela decrescente qualidade de vida em meio urbano (Tapia-Granados, 1998).

Juntamente com a incorporação do automóvel no cotidiano das comunidades, surge um importante problema social, os AT. Enquanto no mundo desenvolvido faz-se um esforço considerável no sentido de controlá-lo, nos países em desenvolvimento ele aparece como um problema cada vez maior. No caso do Brasil, o trânsito é considerado um dos piores e mais perigosos do mundo. Os índices de AT são altíssimos, com um para cada lote de 410 veículos em circulação. Na Suécia, a relação é de um AT para 21.400 veículos em trânsito (DENATRAN, 1997).

Uma frota de veículos cada vez maior, circulando no mundo inteiro, trouxe, além dos AT, um aumento significativo na poluição do ar, no índice de ruídos e na transformação degradante da paisagem urbana. $O$ excesso de gases liberados pelos motores dos automóveis concorre decisivamente para uma proporção considerável das doenças respiratórias. $\mathrm{Na}$ Re- gião Metropolitana de São Paulo, por exemplo, o número de dias com índices inadequados de concentração de poluentes já alcança cerca de $10 \%$ do total.

Um outro aspecto a ser considerado referese à perda de qualidade de vida, causada pela impossi bilidade de encontrar espaços destinados à convivência social diante da crescente construção de espaços exclusivamente para os veículos.

Em adição, no Brasil, nos últimos anos, em decorrência da estabilidade econômica, o volume de carros tem aumentado significativamente, situação esta compatível com um crescimento de cerca de $20 \%$ no consumo de combustíveis.

Além de representar um grande problema de saúde pública, os AT implicam um custo anual de $1 \%$ a $2 \%$ do produto interno bruto para os países menos desenvolvidos (Soderlund \& Zwi, 1995). Numa estimativa conservadora, o Governo do Estado de São Paulo (1993) calcula que o custo social e material dos AT chega a cerca de $1 \%$ do PIB nacional. Nos EUA, uma análise da Administração da Segurança no Tráfego nas Estradas Nacionais concluiu que os principais custos em decorrência de AT correspondem a dano de propriedade (33\%), perda de produtividade no trabal ho (29\%), despesas médicas ( $10 \%$ ) e perdas de produtividade no lar (8\%) (CDC, 1993).

As deficiências físicas resultantes de AT trazem graves prejuízos ao indivíduo (financeiros, familiares, de locomoção, profissionais etc.) e para a sociedade (gastos hospitalares, diminuição de produção, custos previdenciários etc). As estimativas da Organização Pan-Americana de Saúde (OPS) apontam que $6 \%$ das deficiências físicas são causadas por AT no mundo. No Brasil, do total de portadores de deficiências atendidos pelo Hospital das Clínicas de São Paulo, 5,5\% são casos de vítimas de AT (Governo do Estado de São Paulo, 1993).

No Brasil, cerca de dois terços dos leitos hospitalares dos setores de ortopedia e traumatologia são ocupados por vítimas de AT, com média de internação de vinte dias, gerando um custo médio de vinte mil dólares por ferido grave (Pires et al., 1997). O Departamento Nacional de Trânsito (DENATRAN) registrou, em 1994, mais de 22 mil mortes no trânsito no País e mais de 330 mil feridos. O custo anual estimado ultrapassa três bilhões de dólares (Pires et al., 1997).

Esses números expressam bem o drama social decorrente da motorização em sociedades em desenvolvimento, como o Brasil, e a necessidade premente de se trabalhar a questão da 
segurança no trânsito. Em âmbito mundial, essa questão só passou a ser examinada com interesse correspondente à sua importância a partir da década de 50; no Brasil, porém, é ainda mais recente, e está sendo implementada por meio de campanhas em nível federal, estadual e municipal. A aprovação pelo Congresso Nacional do novo Código de Trânsito em 1998 é um começo promissor de mudança quanto a esses altíssimos números. Contudo, programas adicionais são imprescindíveis para criar uma nova cultura no trânsito e, nesse aspecto, somente os municípios maiores nas regiões mais desenvolvidas têm encontrado condições de implementar tais programas.

\section{Aspectos epidemiológicos e econômicos}

\section{Mortalidade no Trânsito}

O aumento da mortalidade por AT, bem como a gravidade das lesões que os mesmos causam, começaram a ser destacados pelos pesquisadores de países desenvolvidos a partir da década de 60. A Organização Mundial da Saúde (OMS) observa que o índice de mortalidade entre pedestres com mais de 14 anos de idade diminui, aumentando significativamente entre motoristas e ocupantes de veículos, principalmente após os 17 anos de idade (WHO, 1976). No Brasil, Mello-Jorge \& Latorre (1994), considerando apenas as áreas geográficas de melhor qualidade de informação, observaram que os atropelamentos ocupam entre $50 \%$ e $85 \%$ das mortes por AT. No Rio de Janeiro, Klein (1994) verificou que os atropelamentos, em 1990, representaram $55 \%$ dos óbitos por AT no grupo de 20 a 39 anos, e 86\% no dos maiores de 65 anos.

Yunes \& Rajs (1994), estudand o a mortalidade por causas violentas nas Américas, observam que, embora a mortalidade proporcional por AT neste grupo de mortes tenha apresentado tendência decrescente, ainda constitui um problema grave no Brasil, Canadá, EUA eVenezuela. Nos EUA, $72 \%$ de todas as mortes de adolescentes e adultos jovens são causadas por violências, que incluem AT, outras lesões não intencionais, homicídios e suicídios (CDC, 1995). No Brasil, o coeficiente de mortalidade por acidentes de trânsito, em 1994, era de 18,9 (por cem mil habitantes), sendo superior ao dos EUA $(18,4)$, da França $(16,5)$, da Argentina $(9,1)$, entre outros. Em números absolutos, os óbitos por AT aumentaram de 17.795, em 1977, para 29.014, em 1994. A situação epi demiológica das diversas capitais brasileiras é heterogê- nea, mas em $50 \%$ dos casos houve tendência crescente nesse período, e algumas delas, especialmente as que são pólos de migração, apresentaram um incremento de $100 \%$ ou superior (Mello-Jorge \& Latorre, 1994).

A mortalidade por AT no Brasil tem flutuado entre 16,1/ 100.000 em 1994 e 18,9/100.000 em 1994, sendo que al gumas localidades apresentam taxas até duas vezes mais elevadas, como é o caso de Goiânia, Campo Grande, Vitória, Curitiba, Florianópolis e Distrito Federal (Mello-Jorge et al., 1997). O Brasil presenciou no ano de 1997 um número superior a $38 \mathrm{mil}$ mortos e 460 mil feridos, num conjunto total de 2,1 milhões de AT. De 1992 a 1996, houve um acréscimo de $24 \%$ no número de mortes por AT (DENATRAN, 1997), sendo o índice de fatalidade, pelo menos, duas vezes maior do que o encontrado em países desenvolvidos. Exemplo disso é o índice de 8,8 mortes encontrado no Japão, que vem apresentando redução de ano para ano, enquanto no Brasil tem ocorrido exatamente o inverso.

Reichenheim \& Werneck (1994), ao analisar os grandes grupos de causa de óbitos no Município e no Estado do Rio de Janeiro em 1990, observaram que as causas externas são o principal motivo de mortalidade precoce, predominantemente entre representantes do sexo masculino. Como causa isolada, os AT foram responsáveis por $7,6 \%$ das mortes precoces no Estado e por 8,3\% no Município do Rio de Janeiro. Enquanto isso, na cidade de São Paulo, os AT representam a quinta causa de morte prematura (PMSP, 1992).

Em Recife, em 1991, Lima \& Ximenes (1998) descreveram maior mortalidade por AT no estrato de condição de vida mais elevado e maior acometimento da população de cinqüenta anos e mais.

\section{Morbidade e incapacidade}

Quanto às estatísticas de morbidade, a subnotificação é bastante relevante, uma vez que só são incluídos os AT que chegam ao conhecimento da polícia. Nos EUA, em 1990, aproximadamente $22 \%$ dos 5,4 milhões de pessoas envolvidas em acidentes de trânsito não fatais não fizeram ocorrência policial (CDC, 1993). A deficiência de dados sobre os AT constitui um obstáculo importante para o desenvolvimento dos programas de segurança no trânsito, já que prejudica a configuração e a análise do problema.

Soderlund \& Zwi (1995) analisaram dados relativos às mortes por AT em 83 países durante o ano de 1990 e observaram que, quanto maior o Produto Nacional Bruto (PNB) per ca- 
pita, mai or é o orçamento destinado ao atendimento de saúde e menores são as taxas de letalidade entre as vítimas de AT. Havendo melhor qualidade de tratamento, haverá maior probabilidade de sobrevida (WHO, 1976).

Embora a OMS recomende que se incluam nas estatísticas as mortes em decorrência de AT ocorridas após trinta dias do acidente, alguns países só consideram os óbitos até o sétimo dia (OMS, 1984). Em descompasso com a orientação da OMS, a Associação Brasileira de Normas Técnicas (ABNT) recomenda que a morte seja registrada até três dias após o acidente (Clark, 1995). Sendo assim, no Brasil, muitas das vítimas de AT vão a óbito sem que este seja registrado como conseqüência de AT.

Há que se considerar ainda que muitos dos acidentados admitidos em hospitais não são identificados como vítimas de AT, mas como de acidentes em geral. Esses motivos explicam por que o registro oficial de mortos no trânsito, especialmente no caso de países em desenvolvimento como o Brasil, não aponta um número real (Braga \& Santos, 1995). De acordo com Clark (1995), no caso brasileiro, o sub-registro é bastante elevado, variando de $35 \%$ a $100 \%$, conforme a região do País.

O número de incapacitados por AT tem aumentado significativamente. Entre as explicações para esse fenômeno observa-se: a) maior número de AT entre jovens que apresentam melhores condições de saúde para sobreviver aos acidentes graves; b) maior velocidade dos veículos; c) aumento do número de veículos pesados; d) avanços nas técnicas médicas de ressuscitamento.

Um levantamento no Reino Unido, com base em 4.342 internações no Hospital de Acidentados de Birmingham, em 1961, observou que mais da metade das incapacidades atingiam menores de trinta anos; perto de um terço destas foi grave e metade, moderada, tendo como vítimas $25 \%$ de motociclistas, $21 \%$ de pedestres, $21 \%$ de ocupantes de veículos e $11 \%$ de ciclistas (WHO, 1976). No Brasil, em 1988, Campos-da-Paz et al. (1992) identificaram, em 36 hospitais públicos, 108 pacientes ( $81 \%$ do sexo masculino) com lesão medular por trauma, sendo $42 \%$ dos casos decorrentes de AT.

A Organização Pan-Americana da Saúde (OPS, 1994) estima que a cada adolescente que morre por AT, entre 10 a 15 apresentam seqüelas graves, e 30 a 40 sofrem ferimentos graves, devendo utilizar serviços de emergência e/ ou reabilitação.

\section{Sexo e idade}

Em $73,1 \%$ dos casos, os principais envolvidos em AT são pessoas do sexo masculino. Os jovens são as principais vítimas, e a faixa etária que contém um número mais significativo destas, com $24,32 \%$ do total, é a que vai dos 15 aos 24 anos (DENATRAN, 1997). Klein (1994) mostra o predomínio masculino de mortes no trânsito, em especial no grupo de 20 a 64 anos, que atinge cinco vezes mais homens do que mulheres. No período de 1977 a 1989, a tendência média da mortalidade por AT foi de leve ascensão, quase exclusivamente em razão do aumento das mortes de vítimas do sexo masculino (em todas as faixas etárias), exceto no Rio de Janeiro, onde o sexo feminino também apresentou tendência crescente (Mello-Jorge \& Latorre, 1994).

Murray \& Lopez (1996), ao analisarem a mortalidade no sexo masculino, utilizando o cálculo de anos potenciais de vida perdidos (APVP), observaram que os AT constituem a segunda causa de morte precoce no mundo todo. Em alguns países, os óbitos por AT entre homens de 15 a 24 anos representam metade ou mais das mortes por todas as causas, havendo uma diminuição após os 25 anos de idade (WHO, 1976).

Na França, o inquérito Baromètre Santé, realizado em novembro de 1992, que incluiu 315 jovens entre 18 e 24 anos, menciona que, entre estes, os AT são o problema de saúde mais importante (69,3\%). Três de cada quatro mortes na faixa de 15 a 19 anos são causadas por AT, e, embora corresponda a $10,5 \%$ da população, essa faixa etária contém $25 \%$ das vítimas dos acidentes de trânsito. Ainda em 1992, na faixa de 18 a 24 anos, as estatísticas de AT apontavam: 2.315 mortes, 11.997 ferimentos graves e 40.809 ferimentos leves (Baudier et al. 1994).

Nos EUA, os jovens também são as maiores vítimas no trânsito. Segundo estatísticas de 1983, 50\% dos motoristas envolvidos em acidentes fatais pertenciam à faixa de 16 a 29 anos (Williams \& Carsten, 1989). Hakkinen (1976, apud Kaiser, 1979), por sua vez, observou que, em todas as faixas etárias, a freqüência de acidentes é uma vez e meia maior nos três primeiros anos em que o motorista adquire sua carteira (licença) para dirigir, do que nos anos subseqüentes. Uma vez que juventude, pouca prática na condução de veículos e falta de adaptação geral no trânsito estão fortemente associadas ao maior risco de AT (Kaiser, 1979), o grupo etário mais atingi do é o de jovens, tendo em vista o fato de que é nessa fase que con- 
seguem a licença (Carteira de Motorista) e, concomitantemente, têm menor experiência para dirigir.

Yunes \& Rajs (1994) mostram que, nas Américas, entre 1984 e 1994, houve um aumento dos coeficientes de mortalidade, especialmente nas faixas de 15 a 19 e de 20 a 29 anos, tanto em homens, como em mulheres, embora nos homens o maior coeficiente seja noventa e nas mulheres inferior a seis (por cem mil habitantes). Entre 1970 e 1985, a mortalidade proporcional por violências e acidentes, no Município de São Paulo, variou de 8,9\% para 13,0\% para ambos os sexos; de $12,6 \%$ para $18,5 \%$ para os homens e de $4,3 \%$ para $5,2 \%$ para as mulheres. O índice de sobremortalidade masculina manteve-se constante em 3,3. Os óbitos por causas violentas ocupavam, em 1985, o segundo lugar na estrutura das principais causas de mortalidade masculina, sendo especialmente freqüentes entre os jovens de 15 a 29 anos (Pagliaro, 1992).

Anteriormente, um grupo de pesquisas (OECD Research Group), com base no estudo do Comitê Europeu de Saúde Pública, observou que a proporção de sexos entre os acidentados no trânsito era de 4,5 homens por cada mulher, e que a maior freqüência era entre 17 e 22 anos (WHO, 1976).

\section{Desenvolvimento econômico}

De acordo com informe da OMS (1984) a respeito de uma análise feita com o objetivo de avaliar o desempenho de diversos países quanto à segurança no trânsito, tem-se que:

1) os países industrializados (que já implementaram várias medi das para conter a violência no trânsito, principalmente a partir da segunda metade da década de 70) têm conseguido estabilizar o problema, mas os custos têm sido crescentes;

2) nos países em um nível intermediário de desenvolvimento, os AT estão entre as principais causas de mortalidade, principalmente entre jovens. Nesses países, os custos com problemas decorrentes de AT representam cerca de $1 \%$ do Produto Nacional Bruto (PNB);

3) em último lugar, os países em desenvolvimento, apesar das preocupações com os problemas gerados pelos acidentes de trânsito, não conseguem implantar políticas ou programas destinados à diminuição da mortalidade ou dos custos dos problemas decorrentes dos AT, os quais representam até $2 \%$ do PNB (Soderlund \& Zwi, 1995).

De acordo com estudo recente do Banco Mundial, apresentado na 3ạ Conferência Anual de Transportes, Segurança de Trânsito e Saúde, promovida pela OMS, em Washington, de cada cem pessoas mortas em AT no mundo, setenta são habitantes de países subdesenvolvidos e 66 são pedestres. Entre estes últimos, cerca de um terço são crianças (Lundebye, 1997). O estudo revela ainda que, das cerca de meio milhão de vidas perdidas anualmente em AT em todo o mundo, os países pobres são responsáveis por 350 mil mortes no trânsito.

Alfaro-Alvarez \& Díaz-Coller (1977) analisaram dados secundários de 28 países das Américas e, ao comparar os anos de 1969 e 1975, observaram uma tendência crescente da mortalidade por AT, diretamente proporcional ao número de veículos registrados. Os AT relacionam-se com o volume de carros circulantes, e, nos países menos desenvolvidos, com baixo índice de veículos, as vítimas de AT são preferencialmente os pedestres. Nos países de maior desenvolvimento, com elevado índice de veículos, as vítimas são os motoristas. Na América do Sul, os atropelamentos fatais respondem por mais da metade das mortes ocorridas no trânsito. Já nas nações ricas, as vítimas mais comuns em AT são os ocupantes dos carros. Nos EUA, por exemplo, atingem $80 \%$ de motoristas e $20 \%$ de passagei ros (Lundebye, 1997). Portanto, nos países pobres, é preciso investir na proteção e educação tanto do pedestre, como do motorista.

Sendo assim, nesse contexto, o grande foco de atenção dos governos deve ser o trânsito nas cidades, visto que dois terços dos AT que causam ferimentos ocorrem em áreas urbanas.

\section{A qualidade de informação}

Mello-Jorge \& Latorre (1994) apontam a dificuldade para estudar os AT por tipo de causa, visto que, em geral, o diagnóstico de causa básica é de natureza não especificada. Entre 1977 e 1987, mais de $70 \%$ dos AT no Brasil estavam nessa categoria. Esses autores destacam a necessidade de mel horia da qualidade da informação em nível dos Institutos M édico-Legais, uma vez que, na mai oria dos casos, tais institutos dispõem de cópia do Boletim de Ocorrência Policial, onde constam as circunstâncias do acidente de trânsito, as quais são fundamentais para especificar a causa básica de morte.

Entre 1984 e 1989, a Organização PanAmericana da Saúde organizou, em países da América Latina, quatro seminários interinstitucionais sobre o estudo epidemiológico dos AT, quando se reconheceu, unanimemente, a necessidade de criar ou aperfeiçoar sistemas de informação para o monitoramento dos AT 
(Bangdiwala et al., 1991). Nesse sentido, o artigo deWaldman \& Mello-Jorge (1999) apresenta uma sistematização dos conceitos e aspectos operacionais fundamentais para um eficiente sistema de vigilância das violências, incluindo os AT.

\section{Personalidade e AT}

Vários estudos revelam conexão significativa entre personalidade e risco de AT. Uma pesquisa na Austrália, por exemplo, comparou cem indivíduos culpados de acidentes graves com cem controles pareados. Os casos apresentaram maior freqüência de sintomas psiquiátricos menores, como ansiedade, impulsividade e falta de consciência social. Referiram, também, com maior freqüência, eventos de vida desfavoráveis nas quatro semanas prévias ao acidente (WHO, 1976).

Tem sido observada ainda uma associação significativa entre criminalidade e envolvimento em AT. Pesquisa de Haviland \& Wiseman (Haviland \& Wiseman 1974, apud West et al., 1993b) observou que 114 criminosos apresentavam 5,5 vezes maior envolvimento em AT com danos materiais ou lesionados e 19,5 vezes maior envolvimento em AT fatais. A classificação de transtornos mentais do Manual Diagnóstico e Estatístico deTranstornos Mentais (DSM-IV, 1995) inclui o "dirigir imprudente" na categoria de desordens de personalidade anti-sociais, considerando-o como um sinal indicativo desta classe de desordens, juntamente com a falta de sentimento de culpa, o não-pagamento de dívidas e o comportamento criminal (West et al., 1993b).

McGuire (1972, apud West et al., 1993b) estudou 2.727 solicitantes de cartei ra de motorista através de testes e questionários e levantou a incidência de acidentes nos dois anos subseqüentes. Observou que o envolvimento em acidentes associava-se com sentimentos de hostilidade, agressividade e antecedentes de conflitos familiares.

Evans et al. (1987, apud West et al., 1993b), em estudo com motoristas de ônibus na Índia e nos EUA, encontraram que os de comportamento hiperativo, agitado e nervoso (convencionalmente denominados de tipo A), em ambos países, apresentavam taxas de acidente mais elevadas que os de comportamento passivo, controlado e calmo (convencionalmente denominados de tipo B). Na Índia, também foi observado que os motoristas de personalidade tipo A brecavam, ultrapassavam e tocavam a buzina com maior freqüência.
Sobre a vulnerabilidade do adolescente e sua busca da identidade adulta, cabe lembrar os trabalhos de Erik Erikson (Erikson, 1972) e, entre nós, sul-americanos, os de Knobel (1980). Um estudo de Manstead et al. (1991, apud Parker et al., 1995) com adolescentes e jovens observou que estes não apresentam falta de habilidades nas tarefas de direção simulada, mas suas respostas a um questionário nem sempre mostraram atitudes e opiniões compatíveis com uma direção segura.

Quimby et al. (1986, apud West et al., 1993a) comentam que os estudos não têm conseguido demonstrar relações consistentes entre o desempenho psicomotor e a tendência para sofrer acidentes, o que tem levado a uma concepção de que o estilo de conduzir pode ser mais importante que as habilidades psicomotoras.

As ocorrências de AT concentram-se em um grupo pequeno dos condutores. Pesquisa na Alemanha observou que $9 \%$ dos condutores eram responsáveis por $40 \%$ dos acidentes (Kaiser, 1979). Meyer \& Jacobi (1961, apud Middendorf, 1976), em levantamento de 145.000 atas de companhias seguradoras, observaram que:

a) os acidentes do trânsito se qualificam como infrações culposas ou premeditadas contra os regulamentos de trânsito mais simples e, em geral, acontecem em circunstâncias cotidianas de trânsito. Parte dessas infrações levam, inevitavelmente, a acidentes;

b) as motivações internas de erro humano observadas são: dificuldades ou falta de disposição para a obediência às normas jurídicas do trânsito.

A freqüência relativa de AT com relação ao total de portadores de carteira de motorista vai diminuindo com o aumento da idade: na Alemanha, observaram-se $10 \%$ de acidentes graves na faixa etária de 19 e 20 anos, mas esta cifra caiu para $4 \%$ no grupo de pessoas entre 25 e 34 anos, que constituem a maioria dos motoristas (Kaiser, 1979). Os adolescentes apresentaram maior freqüência de infração por dirigirem de forma temerária, por estarem entediados, com desejo de aventura ou com vontade de se destacar (Middendorf, 1976).

Como foi observado na Conferência de Roma (OMS, 1984), o comportamento do motorista é o principal fator responsável por AT (observação de sinais, velocidade e decisões no momento de ultrapassar outro carro ou de cruzar uma rua). Concluiu-se, nesse evento, que é necessário um conhecimento maior das culturas e das condições de vida locais para que as atitudes dos motoristas possam ser compreendidas, aproveitando esse conhecimento em programas de capacitação, reabilitação e 
educação, que promovam um comportamento mais adequado.

\section{Agressividade e transgressão}

Vários estudos verificam uma forte conexão entre agressividade e trânsito, principalmente entre a população jovem e adolescente. Para Denker (1966, apud Middendorf, 1976), a frustração provoca diferentes reações, sendo a agressividade uma delas. Desejo de segurança, novas experiências, compreensão, reconhecimento e justiça, quando não satisfeitos, podem, no adolescente, levar à frustração que, por sua vez, pode levá-lo a comportamentos anti-sociais.

No adulto, persistem, em forma residual, aspirações primitivas de poder. Em alguns indivíduos, características infantis os fazem procurar por um instrumento que Ihes permita multiplicar suas possibilidades físicas. O carro, nesse sentido, representa um prolongamento do corpo do motorista e se torna parte integrante de seu narcisismo (Raix et al., 1982).

Para Hess \& Haeberli (1967, apud Middendorf, 1976), a agressão e a tendência à procura por riscos estão estreitamente associadas. Em tempos primitivos, o enfrentamento de situações de risco constituía, freqüentemente, uma questão de sobrevivência. Hoje, o homem procura riscos artificiais para seu prazer no tempo livre, entre eles, o mais facilmente disponível, o veículo.

A transgressão é uma infração intencional do socialmente aceito e regulado. Para Manstead et al. (1991, apud Blockey \& Hartley, 1995), as transgressões são reflexo de que o condutor acredita que suas atitudes e comportamentos estão certos. Assim, a identificação da natureza de tais atitudes e crenças é fundamental para o planejamento, educação e prevenção delas, precisando haver mudanças de atitudes, crenças, normas e, ao mesmo tempo, a divulgação adequada da cultura de segurança (Reason, 1990, apud Parker et al., 1995).

As transgressões no trânsito são um fenômeno social e devem ser analisadas no contexto organizacional e social mais amplo. Atualmente, os comportamentos não ajustados de autodestruição, como o alcoolismo e a drogadicção, apresentam-se com maior freqüência. Nessa circunstância, o carro pode se constituir num instrumento de escapismo e num meio de violência (Baudier et al., 1994).

Parker et al. (1995) realizaram pesquisa com 1.600 motoristas e identificaram três tipologias de comportamentos aberrantes ao dirigir: 1) lapsos ou comportamentos de esqueci- mento; 2) erros de julgamento ou observação potencialmente perigosos para outros; 3 ) transgressões, contravenções intencionais às práticas de seguridade no trânsito. A pesquisa concluiu que os homens, em maior freqüência que as mulheres, referiram elevado número de erros. As mulheres relataram mais lapsos, em associação à percepção de si como más motoristas. Quanto às transgressões, estas se associaram à juventude, ao sexo masculino, à autoqualificação como bom motorista (acima da média) e à elevada quilometragem anual.

Blockey \& Hartley (1995) realizaram um estudo com 67 homens e 74 mulheres, cuja análise fatorial destaca três fatores: erros gerais, erros perigosos e transgressões perigosas. Os condutores jovens cometeram erros e transgressões perigosos com maior freqüência. Os homens referiram maior freqüência de transgressões perigosas, enquanto os condutores com exposição à estrada e aqueles que tinham sido detidos por alta velocidade relataram maior freqüência de transgressões perigosas.

West et al. (1993b) estudaram, mediante aplicação de questionário, o "desvio social leve", caracterizado por comportamentos que predispõem o indivíduo a AT. O desvio social (em que os homens tiveram pontuação mais elevada do que as mulheres) teve correlação positiva com o índice de acidentes, independentemente de idade, sexo, e quilometragem anual. O desvio social apresentou uma associação negativa com meticulosidade e positiva com velocidade e comportamento indevido na direção. O comportamento tipo A associou-se positivamente com velocidade na direção, mas não houve evidência de associação com maior risco de acidente.

Há várias explicações do porquê de indivíduos com comportamento desviante dirigirem mais rápido e, conseqüentemente, causarem mais acidentes. O desvio social pode ser motivado por uma ênfase indevida nas necessidades imediatas, sem qualquer consideração às conseqüências futuras para si ou para outros. Uma outra explicação é que exceder os limites de velocidade significa desafiar a lei e, para os indivíduos com desvio social mais elevado, esse comportamento representa uma forma de auto-afirmação compensatória.

\section{Tomada de decisão}

Kaiser (1979) dá importância especial à tomada de decisão no trânsito, a qual sofre intervenção de percepção, juízos, motivações e outras atividades psíquicas. As situações de trânsito obrigam o indivíduo a tomar decisões em fra- 
ções de segundos, dentro de uma multiplicidade de impressões do mundo circundante, e encaixá-las no mosaico das situações momentâneas. Desse modo, pode-se tomar uma decisão inadequada em razão de uma perturbação transitória, como nos casos de fadiga, estresse, sobrecarga emotiva ou embriaguez.

French et al. (1993) observam que os fatores prognósticos de envolvimento em AT (considerando a quilometragem anual) incluem idade, experiência, habilidade para observar rapidamente situações de risco e tendência a correr riscos. Acreditam que o envolvimento em acidente pode ter mais relação com o modo como as pessoas fazem julgamentos e tomam decisões, do que com sua habilidade para controlar o carro. Exemplos de tomadas de decisão no trânsito incluem a ultrapassagem, a mudança de pista, estacionar o veículo numa brecha de tamanho determinado, entre outras.

Uma forma importante de abordar o estudo da tomada de decisão está relacionada aos aspectos sociológico/ antropológico (em que se enfatiza o exame de crenças e valores do motorista) e psicológico (em que se enfatiza características da personalidade baseadas numa certa tipologia). Neste último caso, segundo o modelo de Career (1992, apud French et al., 1993), os indivíduos classificam-se em três tipos: racionais, intuitivos e dependentes. A tomada de decisão racional caracteriza-se por destacar a informação relevante, observar cuidadosamente as conseqüências futuras e atuar de forma intencional e lógica. A intuitiva mostra pequena antecipação às conseqüências futuras, ou pequena procura sistemática de informação. A dependente tem como característica não se mostrar responsável por suas decisões, que são tomadas em virtude da aprovação social.

O estudo de French et al. (1993) concluiu que condutores que apresentaram um grau menor de meticulosidade em tomadas de decisão mostraram um risco maior de AT e esta associação esteve mediada pela maior velocidade na direção. Os jovens até trinta anos apresentaram um índice mais elevado de falta de meticulosidade. Dessa forma, os autores acreditam que a baixa meticulosidade é reflexo de um traço mais geral de impaciência, que pode conduzir as pessoas a dirigir com maior velocidade.
Velocidade, medidas de segurança e prevenção de AT

\section{Velocidade}

A velocidade que o carro permite atingir oferece ao condutor a oportunidade de experimentar sentimentos de grandeza e fantasia de onipotência; além disso, música no carro favorece a sensação de isolamento e, assim, aumenta a sensação de grande independência. Autores que se preocupam com uma abordagem psicanalítica do problema têm apontado a vulnerabilidade de adolescentes e adultos com personalidade imatura na condução perigosa de veículos motorizados. O carro constitui uma compensação para o ego angustiado e apático e torna-se uma segunda pele do indivíduo. Nesse sentido, o automóvel passa a exercer a função de separar o motorista de seus semelhantes, que são visualizados exclusivamente como oponentes (Hilgers, 1993).

Um outro aspecto importante de se observar é a influência da publicidade sobre o comportamento e formação de valores. Ainda segundo a OMS (WHO, 1976), freqüentemente veiculam-se anúncios que associam carros velozes e altas velocidades com virilidade. Esses anúncios podem ter grande influência no grupo de risco de jovens motoristas, em razão da vulnerabilidade destes, determinada pela própria condição de transformação da personalidade. Erros no julgamento de distância ou de tempo e fatos inesperados, como buracos ou chão escorregadio, convertem-se em acidentes por causa do excesso de velocidade.

A correlação positiva entre velocidade e maior risco de AT já foi verificada por várias pesquisas (French et al., 1993). Quanto ao excesso de velocidade, Hilgers (1993) observa que a falta de fiscalização nas estradas denota um descaso das autoridades em relação ao perigo dos AT. A negação do perigo inerente ao carro também se manifesta na ausência de políticas de transporte adequadas. Em 1989, nas estradas alemãs, existiam seiscentos pontos de controle de velocidade, o que representava um a cada $30.000 \mathrm{~km}$ e, assim, a probabilidade de detectar infratores era irrisória.

O Inquérito Europeu de Saúde e Comportamento, realizado no Reino Unido, revelou que $17 \%$ dos homens poucas vezes respeitam o limite de velocidade e que a freqüência de mulheres nesta faixa foi significativamente menor (2,3\%) (Wardle \& Steptoe, 1991). A crença de que dirigir dentro do limite de velocidade é importante para a saúde é pouco difundida, sendo apenas relatada por 7,9\% das 
mulheres e 6,7\% dos homens ( Wardle \& Steptoe, 1991).

Em estudo na Nova Zelândia, com 217 motociclistas de 18 anos, observou-se que mais de $22 \%$ tinham sido multados, principalmente por alta velocidade. Embora $46 \%$ da amostra fossem portadores da carteira de habilitação especial para jovens, a maioria referia ter violado as restrições impostas por esta (Reeder et al., 1996).

West et al. (1993a) aplicaram um questionário sobre estilo de direção a 48 condutores, os quais foram também observados (sem que soubessem) em uma rota pré-definida em setor urbano e de estrada. A velocidade determinada por observadores na estrada correlacionou-se bem com a velocidade habitual de direção referida pelo condutor. Esse estudo utilizou uma regressão logística múltipla, considerando, como variável dependente, o antecedente de envolvimento em acidente. A velocidade observada na estrada, independentemente das outras variáveis, esteve significativamente associada com envolvimento em acidente.

\section{Medidas de segurança e prevenção}

As crenças relacionadas à manutenção da saúde são importantes em si mesmas como um fator que determina comportamentos de saúde. Dentre estes, de importância na prevenção de AT, podemos citar o hábito de não ingerir bebidas al coólicas ao dirigir e o uso de cinto de segurança. Crenças sobre a importância de hábitos de saúde não só influenciam comportamentos, mas também são importantes nas atitudes em relação à legislação, bem como nas decisões de políticas sociais e nos programas de promoção de estilo de vida saudável.

Os comportamentos inadequados no trânsito parecem constituir uma categoria difícil de ser mudada, mas, segundo Parker et al. (1995), o Reino Unido é exemplo de que é possível conseguir grandes conquistas no comportamento relacionado a beber e dirigir. De acordo com os autores, esse exemplo serve para mostrar que tal objetivo requer muito esforço, tempo e dinheiro, mas que se pode mudar esse tipo de atitude

Nos EUA, o CDC - Centers for Disease Control (CDC, 1994) comenta que, desde 1966, quando o Governo Federal estabeleceu que a segurança nas rodovias era uma prioridade nacional, o número anual de mortes por AT diminuiu em $21 \%$, embora o número anual de quilômetros percorridos por veículos tenha aumentado em $114 \%$. A redução da freqüência das lesões de AT tem sido associada a um conjunto de políticas públicas que têm como base avanços científicos em que se destacam: programas de informação pública; promoção de mudanças comportamentais; mudanças na legislação e avanços de engenharia e tecnologia relacionadas com o trânsito. Essas estratégias têm tido como resultado veículos mais seguros, modificações de práticas de direção (diminuição da freqüência de condutores alcoolizados e aumento do uso de cinto de segurança) e ambiente de estrada mais seguros, bem como meIhoria nos serviços médicos de emergência. Tem sido fundamental nesse sentido a incorporação de sistemas nacionais de coleta de informação para o monitoramento rotineiro dos acidentes fatais, a identificação de fatores de risco modificáveis, a elaboração e implementação de medidas preventivas e a avaliação da efetividade destas. Para Winston et al. (1996), esses avanços aconteceram nos últimos trinta anos, mas ainda há lacunas de conhecimento que limitam a efetividade da prevenção.

O Inquérito Europeu sobre Saúde e Comportamento foi realizado com estudantes universitários de carreiras não médicas (duzentos homens e duzentas mulheres de 18 a 30 anos) de vinte centros participantes. $O$ estudo revela que as mulheres referem dirigir dentro do limite de velocidade regulamentar. A análise das crenças sobre diferentes atividades importantes para a manutenção da saúde mostra que o não beber e dirigir e o uso de preservativo sexual são os mais importantes dentre os 25 itens estudados. No entanto, há discrepâncias importantes entre comportamentos e a força das crenças. Por exemplo, mesmo os que admitem dirigir sob efeito do álcool acreditam ser importante não dirigir após beber. A influência que o conhecimento sobre a saúde tem no estilo de vida pode ser afetada, ainda, pelo contexto social e por variáveis de ordem cultural (Wardle \& Steptoe, 1991).

O uso de cinto de segurança é um comportamento indicativo de interesse na segurança pessoal. Evans \& Bloomfield-Hills (1996) destacam a importância dos meios de proteção, como o cinto de segurança ou air bags, radicais na diminuição da letalidade dos acidentes vitimando ocupantes de veículos, mas afirmam que tais meios não têm qualquer impacto na prevenção dos AT relacionados com pedestres ou ciclistas.

Um inquérito realizado no Reino Unido por Wardle \& Steptoe (1991) observou que o uso do cinto de segurança está amplamente difundido, tanto entre homens, como entre mulheres ( $86,7 \%$ e $89,5 \%$, respectivamente), 
embora a crença sobre a importância dessa ação para a saúde seja pouco freqüente (8,8\%). Nos EUA, os resultados do Sistema de Vigilância de Comportamento de Risco dos Jovens (YRBSS), em 1993, sugerem que muitos estudantes apresentam comportamentos que aumentam seu risco de morte por AT: 19,1\% nunca ou quase nunca usam cinto de segurança, e $35,3 \%$ referem ter andado de carro com condutor alcoolizado nos trinta dias prévios ao inquérito (CDC, 1995).

No que diz respeito a programas de prevenção de AT no Brasil, destaca-se o trabalho de Adorno (1989), que realiza uma revisão dos modelos de comportamento das propostas humanistas de educação em saúde e prevenção de AT. Esse estudo faz, também, um levantamento das propostas técnicas e projetos para as campanhas realizadas e as medidas dirigidas ao aumento da segurança do pedestre.

Sono, medicamentos psicoativos, drogas ilícitas e álcool

Embora o sono seja um elemento dos mais importantes na causa de AT, ele é muito pouco estudado, principalmente pela dificuldade de se pesquisar essa variável após a ocorrência de um acidente.

Leger (1994) comenta que os informes de índices de acidentes relacionados ao sono diferem significativamente de um autor a outro, para condutores com ou sem problemas de sono. Os autores calculam duas taxas para estimar o número de acidentes por veículo a motor causados por sonolência. A primeira é baseada na percentagem total de acidentes e o total de acidentes fatais que ocorrem nas horas de maior sonolência, das $2 \mathrm{~h}$ às $7 \mathrm{~h}$ e das $14 \mathrm{~h}$ às $17 \mathrm{~h}$ ( $41,6 \%$ do total e $36,1 \%$ dos fatais). A segunda é a percentagem do total de acidentes ocorridos à noite (54\%), quando o tempo de reação e de desempenho estão consideravelmente diminuídos. A tendência a adormecer é também aumentada pela privação e pela interrupção do sono, sendo o efeito dessa perda acumulativo.

O sub-registro da sonolência existe por diversos motivos: os envolvidos não desejam referir nem aos policiais, nem amigos ou familiares, que eles dormiram na direção, porque isso significa admitir responsabilidade pelo acidente. A sonolência é, muitas vezes, ignorada por falta de reconhecimento do motorista, que atribui o acidente a outras causas, como a má condição climática ou o estado insuficiente de preservação da rodovia.

\section{Consumo de medicamentos}

e drogas ilícitas

Outro fator preocupante relaciona-se ao uso de drogas, porém estudos sobre a influência destas tornam-se pouco viáveis, pela dificuldade de demonstrar sua presença, já que o nível de metabólitos não se correlaciona com seu efeito na capacidade para dirigir. No entanto, tem-se observado que os motoristas que utilizam estimulantes (anfetaminas) apresentam um risco aumentado de AT (WHO, 1976). Skegg et al. (1979), em estudo caso-controle, observaram associação significativa entre acidente grave e uso de tranqüilizantes menores, como Diazepam.

O inquérito Baromètre Santé aponta que os jovens têm uma atitude permissiva com relação às drogas: 90,6\% pensam ser normal usálas, pelo menos uma vez na vida, e 22,3\% já experimentaram algum tipo de tóxico, principalmente a maconha $(98,6 \%)$. Dos jovens entrevistados, $34,3 \%$ dos consumidores de drogas são homens e $13,4 \%$ são mulheres. Os de maior escolaridade referem com maior freqüência consumo de droga do que os com menor escolaridade (Baudier et al., 1994).

\section{Consumo de álcool}

Várias pesquisas apontam uma forte relação entre a ingestão de álcool e AT. Há estudos que observam que concentrações de 50mg/ 100ml de álcool no sangue podem provocar inaptidão para a condução de veículos (OMS, 1984). Exames post-mortem de rotina em acidentados de trânsito observam que uma percentagem importante dos motoristas mortos apresentam alcoolemia elevada. Em vários países, o álcool é responsável por 30\% a 50\% dos acidentes graves e fatais (OMS, 1984), o que é corroborado pelos dados do CDC (1993), os quais apontam presença de álcool em $50 \%$ de AT fatais e graves. Em contraste, o álcool só está presente em 15\% dos acidentes sem lesão (CDC, 1993).

Nos EUA, considera-se que um acidente fatal é relacionado ao álcool se o condutor ou pedestre apresentar, no momento do acidente, uma concentração de al coolemia igual ou superior a 100mg/ dl; esse nível é considerado de intoxicação.

Rehm (1993) relata que, de 321 motoristas estudados, 87 tiveram níveis de etanol acima de $100 \mathrm{mg} / \mathrm{d}$ e nove estavam entre 50 e $100 \mathrm{mg} /$ dl. Dos 87 motoristas intoxicados com nível de etanol acima de $100 \mathrm{mg} / \mathrm{dl}, 71$ eram do sexo masculino e 16 do feminino. $\mathrm{O}$ autor enfatiza a necessidade de intervenção terapêutica em in- 
fratores reincidentes, uma vez que, para eles, medidas como punição e reeducação têm se mostrado insuficientes.

A importância do contexto sócio-cultural fica evidente nas estatísticas de hábito de ingestão etílica nos diversos estados dos EUA, onde o uso de álcool varia entre o máximo de $63,8 \%$ e o mínimo de $25,4 \%$, sendo maior entre os homens (CDC, 1995). Em estudo com adolescentes menores de 18 anos, Alexandre et al. (1990) atribuem a baixa freqüência de acidentes relacionados ao álcool (1,9\%) aos esforços educativos voltados para a direção e o hábito de beber.

A importância de medidas de caráter preventivo fica em evidência no estudo realizado em Ontário por Stoduto \& Adlaf (1996). Esses autores apontam que a tendência decrescente do beber e dirigir, entre 1977 e 1991, foi interrompida após 1991, quando, em razão de uma regulamentação mais flexível tanto na venda, quanto na propaganda de bebida alcoólica, houve um aumento da disponibilidade desta. O estudo de Reeder et al. (1996), com 217 motociclistas de 18 anos na Nova Zelândia, observa que, entre as medidas preventivas de acidentes, menos de $1 \%$ dos entrevistados menciona não dirigir após ingerir bebida alcoólica. A reincidência em infração de trânsito é maior em menores de trinta anos, e todos esses tipos de infração diminuem após essa idade, exceto aquele por dirigir al coolizado, que se mantém constante em todas as faixas etárias, representando cerca de $50 \%$ das reincidências (Goppinger \& Leferenz, 1968, apud Middendorf, 1976).

No inquérito Baromètre Santé, a amostra de jovens focalizada apresenta $75,5 \%$ de bebedores ocasionais (uma a duas vezes por semana, ou finais de semana, ou menos) e $8,3 \%$ de bebedores habituais (três a cinco vezes por semana). Entre esses jovens, 42,2\% referem pelo menos uma bebedeira por ano (Baudier et al., 1994).

Wardle \& Steptoe (1991), em estudo realizado no Reino Unido, observam que $20 \%$ da amostra ingerem bebida alcoólica regularmente. Embora o consumo de álcool não apresente diferenças significativas entre sexos, o comportamento de beber e dirigir é mais freqüente nos homens (15,9\%) do que nas mulheres (5,4\%). A pesquisa observa, ainda, que a crença de nunca dirigir após beber é pouco freqüente $(9,7 \%$ nas mulheres e 9,4\% nos homens). Adicionalmente, um fenômeno que ocorre em vários países é o elevado consumo de álcool no grupo etário entre 18 a 35 anos, em fins de semana.

Quanto maior o consumo geral de álcool, maior a freqüência de beber e dirigir. O consu- mo per capita de álcool absoluto, segundo informações que datam da última metade da década de 80, aumentou na região das Américas, em países como a Colômbia, o Chile, o México, o Panamá e o Brasil, e este último, com um aumento de $31 \%$, foi o que mostrou o maior incremento (Yunes \& Rajs, 1994).

Enquanto a lei, a sociedade e a justiça brasileiras são excessivamente tolerantes com motoristas alcoolizados, na Europa e nos EUA, a lei não faz muita diferenciação entre um motorista alcoolizado que mata uma pessoa e um crime premeditado. Comparado com países que estão mais adiantados na prevenção dos AT, nossa legislação é permissiva e a aplicação da lei, muito morosa. Somente após o Novo Código Nacional de Trânsito, promulgado em fevereiro de 1998, é que se começa a vislumbrar alguma mudança nesse aspecto. Acreditamos que o novo código tem sido importante para a tomada de consciência do problema, mas o controle real dos infratores é limitado, uma vez que a caracterização do estado de embriaguez ficou, na prática, restrito à perícia do Instituto Médico-Legal.

Nos EUA, entre janeiro e junho de 1992, foi real izada uma estimativa de 1.943 mortos por AT na faixa de 21 a 24 anos (CDC, 1993), e 50\% dessa totalidade estavam intoxicados por álcool (CDC, 1993). Stoduto \& Adlaf (1996) descrevem que, em Ontário, 50\% dos acidentes de trânsito estão relacionados ao álcool e constituem a maior causa única de morte e lesão na população jovem.

Stewart et al. (1996) descrevem que os indivíduos bebem por três razões diferentes: 1) para reduzir ou evitar os estados emocionais negativos; 2 ) por motivos sociais, para reunir-se com outros; 3) para facilitar emoções positivas. Ao estudar uma amostra de 314 voluntários, alunos de graduação de Psi cologia de duas universidades do Canadá, esses autores concluíram que a maioria dos entrevistados (85\%) referiram beber. O principal motivo desse comportamento foi o social, embora os homens, principal mente os menores de 21 anos, tivessem apresentado uma pontuação significativa no hábito de beber para facilitar emoções positivas. Cooper et al. (1994, apud Stewart et al., 1996) têm observado que os indivíduos que bebem para diminuir estados emocionais negativos apresentam riscos aumentados de problemas com o álcool.

Em amostra de 1.011 condutores do Reino Unido, Albery \& Guppy (1995) apontam que $14,1 \%$ dos condutores referiam dirigir após ter ingerido bebida alcoólica acima do limite legal, uma ou duas vezes, no último ano, e 10,3\% re- 
feriam não estar em condições de dirigir em três ou mais vezes nos últimos 12 meses. Os condutores mais jovens, mais comumente, referem quantidades de unidades de álcool e freqüência de ingestão que indicam um padrão de comportamento infrator. Foi observado que os condutores transgressores estimam, com maior freqüência, que sua direção é segura quando bebem, fato esse que constitui uma das causas diretas de acidentes. Observou-se, ainda, uma associação significativa entre consumo geral de álcool e comportamento infrator no trânsito. Além disso, a pesquisa constata que a exposição a procedimentos regulamentares, como o bafômetro e as multas por beber e dirigir, não mostram diminuição do comportamento transgressor. Finalmente, a pesquisa conclui que, quanto maior o consumo, maior o prognóstico de comportamento infrator, e quanto maior a ingestão de álcool, maior a estimativa individual de que se pode dirigir com segurança.

Em 1993, no Hospital das Clínicas da Universidade Estadual de Campinas, estudo realizado com cem doentes traumatizados escolhidos aleatoriamente para real ização de etanolemia observou que 36 estavam alcoolizados, sendo a mai oria jovens de 15 a 35 anos, e, entre estes, vinte tiveram acidente automobilístico (Mantovani et al., 1995).

\section{Considerações finais}

Mostramos, neste artigo, as principais implicações que o tráfego de veículos motorizados traz ao meio urbano e à qualidade de vida do indivíduo moderno. Vimos que os AT surgiram como uma epidemia capaz de produzir muitas mortes, ferimentos e incapacidades, gerando custos financeiros e sociais enormes. Concluímos que os acidentes de trânsito variam significativamente conforme a idade, o sexo, o tipo de personalidade e a cultura de indivíduos neles envolvidos. De um modo ainda mais dramático, os AT variam de acordo com o nível de desenvolvimento econômico-social de um determinado país.

No contexto de países desenvolvidos ou em desenvolvimento, a grande diferença nos níveis de AT está estreitamente vinculada à responsabilidade que o poder público tem de implementar políticas adequadas e fazer cumprir a lei. No Brasil, os índices calamitosos de AT estão associados à falta tanto de uma legislação, como de políticas públicas adequadas em relação a esse fenômeno. O Novo Código Nacional de Trânsito constitui um marco dos mais im- portantes para que haja uma modificação dessa triste realidade. Diante do fato de que os AT estão fortemente relacionados com fal ha humana, a despeito das limitações operacionais e das arestas constitucionais que ainda não foram aparadas, o novo código tem o grande mérito de contribuir para tornar o motorista brasileiro mais consciente e responsável ao volante.

Regulamentar e implementar o novo código exigirá um esforço considerável da sociedade e do poder público. Para se punir um motorista infrator, por exemplo, seria necessário conhecer os atenuantes e agravantes constantes do seu prontuário, além de ter equipamentos técnicos que permitissem mensurar a infração. Atualmente, a polícia civil não conta com formação específica suficiente para apurar adequadamente esse tipo de ocorrência. Sem equipamentos fundamentais, tais como o bafômetro ou uma rede informatizada, a maior parte dos infratores ficam impunes. No Estado de São Paulo, por exemplo, pouco mais de um terço das 313 CIRETRANS (Circunscrições Regionais deTrânsito) está informatizada. Nos outros estados, a situação é ainda mais precária.

A implementação de um programa consistente de educação no trânsito, que implica uma nova noção de cidadania, é imprescindível. É também necessário um controle da propaganda, tanto daquela que associa velocidade à vitalidade e à saúde, como da que associa ingestão de bebidas al coólicas à liberdade e ao prazer.

Além da possibilidade de punir o infrator, o novo código prevê a questão da educação no trânsito, que exigirá um esforço considerável de integração de vários órgãos federais, estaduais e municipais, como os Ministérios do Transporte, da Saúde, da Educação, do TrabaIho, da Justiça, e o Sistema Ú nico de Saúde. É previsto que as escolas de ensino fundamental, médio e as universidades contemplem vários tipos de atividades nesse sentido.

A questão referente à educação de reincidentes é outro aspecto importante para a diminuição dos índices de AT. Contudo, a mudança cultural, que trará uma alteração significativa de comportamento e, conseqüentemente, na cultura do trânsito, será um processo que demandará um tempo considerável.

A questão cultural na transformação de valores referentes ao trânsito é da maior importância em qualquer campanha de prevenção de AT. É provável que as multas eletrônicas, inseridas no novo código de trânsito, efetuadas de um modo impessoal, venham proporcionar, até um certo ponto, um obstáculo à cultura do 
“jeitinho" brasileiro de burlar as leis. Até um certo ponto porque há notícias de que alguns poderes locais, em alguns Estados, estão boicotando o novo código ao anistiar as multas em troca de dividendos político-eleitorais. Outras notícias mostram que al gumas categorias profissionais estão tentando obter na justiça isenção de multas no trânsito. O “jeitinho", nesses casos, transcende a dimensão local, mas é de se esperar que ele esbarre em dificuldades legais crescentes.

De qualquer maneira, o novo código de trânsito veio para acrescentar um sentido positivo à nossa realidade contraditória. Se, antes da promulgação do código, o motorista colocava seu bem-estar pessoal acima da lei, hoje é obrigado a pensar no alto custo da multa e nas outras penalidades que sofrerá antes de deci- dir pela infração. Atualmente, não basta ter poder econômico para arcar com a multa, porque a perda da habilitação também está em jogo.

Se o novo código de trânsito veio como um elemento importante na promoção de um trânsito eficiente, é imprescindível que outros fatores de ordem sócio-econômica, cultural, política e administrativa contribuam para o gerenciamento adequado dos AT. Sem um controle da pobreza, do desemprego, da violência e criminalidade urbana, por exemplo, respeitar um sinal de tráfego implica, cada vez mais, risco de ser assaltado. Num nível mais abrangente, a solução do problema de trânsito requer, sobretudo, a implementação de políticas públicas que enfatizem o aspecto social, com destaque para o transporte coletivo e, simultaneamente, restrições ao transporte individual.

\section{Agradecimentos}

Agradecemos à Fundação para o Amparo à Pesquisa do Estado de São Paulo - FAPESP, ao Conselho Nacional de Desenvolvimento Científico e Tecnológico CNPq e ao FAEP/UNICAMP o seu financiamento; aos pesquisadores que contribuíram para o referido projeto, em particular, Palmeron Mendes, Lídia Y. Komatsu, Marisa L. F. Mauro e Marilia Martins Vizzotto. Agradecemos também o apoio recebido do Núcleo de Estudos Psicológicos (NEP/UNICAMP) e, em particular, do Prof. Dr. Joel S. Giglio.

\section{Referências}

ADORNO, R. C. F., 1989. Educação em Saúde, Conjuntura Política eViolência no Trânsito: O Caso da Cidadede São Paulo. São Paulo: Edusp.

ALBERY, I. P. \& GUPPY, A., 1995. The interactionist nature of drinking and driving: A structural model. Ergonomics, 38:1805-1818.

ALEXANDRE, E. A.; KALLAIL, K. J.; BURDSAL, J. P. \& EGE, D. L., 1990. Multifactorial causes of adolescent driver accidents: Investigation of time as a major variable. Journal of Adolescent Health Care, 11:413-417.

ALFARO-ALVAREZ, C. \& DIAZ-COLLER, C., 1977. Los accidentes de tránsito: Creciente problema para la salud pública. Boletín dela Oficina Sanitaria Panamericana, 83:310-318.

BANGDIWALA, S. I.; ANZOLA-PEREZ, E.; GLIZER, M.; ROMER, C. J. \& HOLDER, Y., 1991. Método epidemiológico estructurado para planear la prevención de los accidentes de tránsito. Boletín dela Oficina Sanitaria Panamericana, 111:186-189.

BAUDIER, F.; JANVRIN, M. P. \& DRESSEN, C., 1994. Les jeunes français et leur santé. Opinions, attitudes et comportements. Promotion \& Education, 1:2935. 
BLOCKEY, P. N. \& HARTLEY, L. R., 1995. Aberrant driving behaviour: Errors and violations. Ergonomics, 38:1759-1771.

BRAGA, M. G. C. \& SANTOS, N., 1995. Educação de trânsito: Alterando as regras do jogo. Revista de Administração Municipal, 214:81-100.

CAMPOS-DA-PAZ, A.; BERALDO, P. S. S.; ALMEIDA, M. C. R. R.; NEVES, E. G. C.; ALVES, C. M. F. \& KHAN, P., 1992. Traumatic injury to the spinal cord. Prevalence in Brazilian hospitals. Paraplegia, 30:636-640.

CDC (Centers for Disease Control and Prevention), 1993. Quarterly table reporting alcohol involvement in fatal motor-vehicle crashes. MMWR, 42:215.

CDC (Centers for Disease Control and Prevention), 1994. Deaths resulting from firearm and motorvehicle related injuries, United States, 1968-1991. MMWR, 43:1-42.

CDC (Centers for Disease Control and Prevention), 1995. Youth risk behavior surveillance, United States, 1993. MMWR, 44:1-45.

CLARK, C., 1995. Avaliação de Al guns Parâmetros de Infrações de Trânsito por Motoristas e Policiais. Tese de Doutorado, São Paulo: Faculdade de Saúde Pública, Universidade de São Paulo.

DENATRAN (Departamento Nacional de Trânsito), 1997. Estatísticas Gerais sobre Trânsito. Brasília: DENATRAN.

DSM-IV (Diagnostics Statistics Manual - IV), 1995. Manual Diagnóstico e Estatístico de Transtornos Mentais. Porto Alegre: Editora Artes Médicas.

ERICKSON, E., 1972. Adolescência, Juventude e Crise. Rio de Janeiro: Zahar Editores.

EVANS, L. \& BLOOM FIELD-HILLS, M., 1996. Comment: The dominant role of the driver behavior in traffic safety. American Journal of Public Health, 86:784-786.

FRENCH, D. J.; WEST, R. J.; ELANDER, J. \& WILDING, J. M., 1993. Decision-making style, driving style, and self-reported involvement in road traffic accidents. Ergonomics, 36:627-644.

GOVERNO DO ESTADO DE SÃO PAULO, 1993. Prevenção de Deficiências: Segurança no Trânsito. São Paulo: Programa Estadual de Atenção à Pessoa Portadora de Deficiência/Secretaria da Saúde/ Secretaria de Transportes.

HILGERS, M., 1993. Automobile or the self in traffic. The psychoanalysis of car abuse. Universitas, 1 : 53-67.

KAISER, G., 1979. Delincuencia de Tráfico y Prevención General. Investigaciones sobre la Criminología y el Derecho Penal del Tráfico. Madrid: Espasa-Calpe.

KLEIN, C. H., 1994. Mortes no trânsito do Rio de Janeiro, Brasil. Cadernos de Saúde Pública, 10 (Sup. 1):168-176.

KNOBEL, M., 1980. Síndrome de adolescência normal. In: Adolescência Normal (A. Aberastury \& M. Knobel, org.), pp. 24-62, Porto Alegre: Artes Médicas.

LEGER, D., 1994. The cost of sleep-related accidents: A report for the National Commission on Sleep Disorders Research. Sleep, 17:84-93.

LIMA, M. L. C. \& XIMENES, R., 1998. Violência e morte: Diferenciais de mortalidade por causas externas no espaço urbano do Recife, 1991. Cadernos deSaúdePública, 14:829-840.
LUNDEBYE, S., 1997. Car accidents and mortality in developing countries. In: 3 a Conferência Anual deTransportes, Segurança de Trânsito e Saúde, Anais, pp. 94-116, Toronto: World Health Organization/Karo Linska Institute.

MANTOVANI, M .; BACCARIN, V.; RASKIN, E.; ZAMBRONE, F.; MELLO, S. \& FERNANDES, M., 1995. Etanolemia no traumatizado. Medical Master: Anais de Atualização Médica, 1:203-206.

MELLO-JORGE, M. H. P. \& LATORRE, M. R. D. O., 1994. Acidentes de trânsito no Brasil: Dados e tendências. Cadernos de SaúdePública, 10:19-44.

MELLO-JORGE, M. H. P.; GAWRYSZEWSKI, V. P. \& LATORRE, M. R. D. O., 1997. Análise dos dados de mortalidade. Revista de Saúde Pública, 31:5-25.

MIDDENDORFF, W., 1976. Estudios sobre la Delincuencia en el Tráfico. Madrid: Espasa-Calpe.

MURRAY, C. J. L. \& LOPEZ, A. D., 1996. The global burden of disease in 1990: Final results and their sensitivity to alternative epidemiological perspectives, discount rates, age weights and disability weights. In: The Global Burden of Disease: A Comprehensi ve Assessment of Mortality and Disability for Diseases, Injuries, and Risk Factors in 1990 and Projected to 2020 (C. J. L. Murray \& A. D. Lopez, org.), pp. 247-294, Cambridge: Harvard University Press/World Health Organization/ World Bank.

OMS (Organización Mundial de la Salud), 1984. Accidentes del Tráfico en los Países en Desarrollo. Serie de Informes Técnicos 703. Ginebra: WHO.

OPS (Organización Panamericana de la Salud), 1994. Las Condiciones de Salud en Ias Américas. Washington, D.C.: OPS.

PAGLIARO, H., 1992. Mortalidade no Município de São Paulo: Desigualdade e violência. In: 8o Encontro Nacional de Estudos Populacionais, Anais, pp. 74-89, Brasília: Associação Brasileira de Estudos Populacionais - ABEP.

PARKER, D.; REASON, J. T.; MANSTEAD, A. S. R. \& STRADLING, S. G., 1995. Driving errors, driving violations and accident involvement. Ergonomics, 38:1036-1048.

PIRES, A. B.; VASCONCELLOS, E. A. \& SILVA, A. C., 1997. Transporte Humano: Cidades com Qualidade de Vida. São Paulo: Associação Nacional de Transportes Públicos - ANTP.

PMSP (Prefeitura Municipal de São Paulo), 1992. Programa de Aprimoramento das Informações de Mortalidade no Município de São Paulo. São Paulo: PMSP.

RAIX, A.; PENNEAU, D. \& PROTEAU, J., 1982. Pathologie et contraintes dans la conduite de véhicules. La Revue du Praticien, 32:1191-1197.

REEDER, A. I.; CHALMERS, D. J. \& LANGLEY, J. D., 1996. The risky and protective motorcycling opinions and behaviours of young on-road motorcycles in New Zealand. Social Science \& Medicine, 42:1297-1311.

REHM, C. G., 1993. Failure of the legal system to enforce drunk driving legislation effectively. Annals of Emergency Medicine, 22:1295-1297.

REICHENHEIM, M. E. \&WERNECK, G. L., 1994. Anos potenciais de vida perdidos no Rio de Janeiro, 1990. As mortes violentas em questão. Cadernos deSaúdePública, 10:188-198. 
ROBERTS, I., 1995. What does a decline in child pedestrian injury mean? American Journal of Public Health, 85:268.

SKEGG, D. C.; RICHARDS, S. M. \& DOLL, R., 1979. Minor tranquilizers and road accidents. BMJ , 1:917919.

SODERLUND, N. \& ZWI, A. B., 1995. Mortalidad por accidentes de tránsito en países industrializados y en desarrollo. Boletín dela Oficina Sanitaria Panamericana, 119:471-480.

STEWART, S. H.; ZEITLIN, S. B. \& BARTON-SAMOLUK, S., 1996. Examination of a three-dimensional drinking motives questionnaire in a young adult university student sample. Behavioural Research Therapy, 34:61-71.

STODUTO, G. \&ADLAF, E., 1996. Drinking and driving among Ontario high school students, 1977-1995. Canadian Journal of Public Health, 87:187-188.

TAPIA-GRANADOS, J. A., 1998. La reducción del tráfico de automóviles: Una política urgente de promoción de la salud. Revista Panamericana de Salud Pública, 3:137-151.

WALDM AN, E. A. \& MELLO-JORGE, M. H., 1999. Vigilância para acidentes e violência: Instrumento para estratégias de prevenção e controle. Ciência \& SaúdeColetiva, 4:71-79.
WARDLE, J. \& STEPTOE, A., 1991. The European health and behaviour survey: Rationale, methods and initial results from the United Kingdom. Social Science \& Medicine, 33:925-936.

WEST, R.; FRENCH, D.; KEMP, R. \& ELANDER, J., 1993a. Direct observation of driving, self reports of driver behaviour, and accident involvement. Ergonomics, 36:557-567.

WEST, R.; ELANDER, J. \& FRENCH, D., 1993b. Mild social deviance, Type-A behaviour pattern and decision-making style as predictors of self-reported driving style and traffic accident risk. British Journal of Psychology, 84:207-219.

WHO (World Health Organization), 1976. The Epidemiology of Road Traffic Accidents. WHO Regional Publications, European Series 2. Copenhagen: WHO.

WILLIAMS, A. F. \& CARSTEN, O., 1989. Driver age and crash involvement. American Journal of Public Health, 79:326-327.

YUNES, J. \& RAJS, D., 1994. Tendencia de la mortalidad por causas violentas en la población general y entre los adolescentes y jóvenes de la región de las Américas. Cadernos de Saúde Pública, 10:88125. 